\title{
A UTILIZAÇÃO DO ICA-ATOM COMO PLATAFORMA DE ACESSO, DIFUSÃO E DESCRIÇÃO DOS DOCUMENTOS ARQUIVÍSTICOS DE INSTITUIÇÕES PÚBLICAS
}

\author{
LA UTILIZACIÓN DE ICA-ATOM COMO PLATAFORMA \\ DE ACCESO, DIFUSIÓN Y DESCRIPCIÓN DE \\ DOCUMENTOS DE ARCHIVO DE INSTITUCIONES \\ PÚBLICAS
}

\author{
Eliseu dos Santos Lima * \\ Daniel Flores**
}

\begin{abstract}
RESUMO:
Introdução: A tecnologia da informação vem ocasionando transformações em diversos segmentos da sociedade. $\mathrm{Na}$ área arquivística sua presença é marcante, tanto que ultimamente tem aumentado o quantitativo de instituições que fazem uso de sistemas informatizados, repositórios e plataformas que automatizam atividades como descrição, difusão, e que inclusive proporcionam o acesso ao patrimônio documental arquivístico.

Objetivo: Discorrer sobre as funcionalidades e a utilidade da plataforma International Council Archives - Access to Memory (ICA-AtoM) nas atividades arquivísticas de descrição, difusão e acesso ao patrimônio documental arquivístico.

Metodologia: Pesquisa bibliográfica, elaborada a partir da legislação arquivística, e principalmente, através de investigações resultantes de dissertações de mestrado, artigos publicados em periódicos da área da Ciência da Informação e manuais produzidos pelos membros do Grupo de Pesquisa CNPq-UFSM: Gestão Eletrônica de Documentos Arquivísticos - Ged/A.

Resultados: Constata-se que a plataforma serve tanto para descrever os documentos permanentes, como para proporcionar o acesso à informação registrada em documentos correntes e intermediários, como forma de dinamizar o acesso aos fundos documentais de instituições públicas.

Conclusões: Considera-se que o ICA-AtoM, além de servir à descrição, pode proporcionar um ambiente autêntico para o armazenamento seguro e como fonte de prova dos documentos institucionais digitais e digitalizados, bem como para prover

*Mestrando do Programa de Pós-Graduação Profissional em Patrimônio Cultural da Universidade Federal de Santa Maria (UFSM). Arquivista do Departamento de Gestão Documental da Universidade Federal da Fronteira Sul (UFFS). E-mail: eliseudsI@yahoo.com.br **Docente do Programa de Pós-Graduação Profissional em Patrimônio Cultural e do Curso de Arquivologia da Universidade Federal de Santa Maria (UFSM). E-mail: dfloresbr@gmail.com
\end{abstract}


preservação e acesso a longo prazo, se for interligada a um RDC-Arq, como o Archivematica, por exemplo.

Palavras-Chave: ICA-AtoM. Acesso. Difusão. Patrimônio documental. Instituições públicas.

\section{INTRODUÇÃO}

Por muito tempo prevaleceu entre a comunidade arquivística o consenso de que o software ICA-AtoM poderia ser utilizado somente para descrever, e prioritariamente se fossem documentos permanentes. Essa ideia vem se modificando, tanto que atualmente já há o entendimento de que além da descrição, as funcionalidades dessa plataforma podem ser utilizadas para o acesso ou para a difusão, mesmo que os documentos não sejam descritos. Atualmente, com todo o subsídio fornecido pela Lei de Acesso à Informação (LAl), acredita-se que as atividades arquivísticas como descrição, difusão e acesso podem e devem ser desenvolvidas desde a fase corrente dos documentos, e o ICA-AtoM é uma opção para o atendimento dessas finalidades.

O estudo apresentado a seguir, consiste em pesquisa bibliográfica resultante de parte da revisão de literatura da Dissertação de Mestrado "Arquivos Universitários: o acesso e a difusão dos acervos e serviços dos setores de arquivo das IFES da região sul do Brasil", que vem sendo desenvolvida no Programa de Pós-Graduação Profissional em Patrimônio Cultural da Universidade Federal de Santa Maria (PPGPPC/UFSM) na linha de pesquisa em Patrimônio Documental.

Para construção do referencial teórico foi realizado levantamento para verificar o que já havia sido escrito sobre o tema. Nesse intuito, consultou-se a legislação arquivística que trata sobre a política nacional de arquivos, acesso à informação, uso do meio eletrônico/inserção de documentos digitais em programas de gestão arquivística de documentos e repositórios digitais confiáveis, e principalmente, dissertações de mestrado, artigos publicados em periódicos da área da Ciência da Informação e manuais resultantes de pesquisas realizadas pelos membros do Grupo de Pesquisa CNPq-UFSM: 
Gestão Eletrônica de Documentos Arquivísticos - Ged/A ${ }^{1}$, o qual desenvolve pesquisas em Gestão Arquivística de Documentos Digitais e Preservação Digital, tendo como política a adoção dos referenciais de Software Livre utilizando sistemas como Archivematica, RODA-Repositório de Objetos Digitais Autênticos, SepiaDES, entre os quais vem efetuando estudos sobre as funcionalidades e utilização do Software Livre ICA-AtoM na descrição, difusão e acesso ao patrimônio documental arquivístico.

Para a construção do referencial teórico, foi realizada a técnica de fichamento de citações, sendo essas sistematizadas através da reprodução literal, e identificadas de acordo com categoria de assunto, autor, obra e número de páginas das quais foram retiradas. Dessa forma, foi possível sistematizar os capítulos que são apresentados na comunicação a seguir, a qual se subdivide em três partes, iniciando com a apresentação do Sistema Nacional de Arquivos (SINAR), seguido da explanação quanto à plataforma ICA-AtoM e finalizando com considerações acerca da utilização dessa ferramenta.

Nesse sentido, no capítulo a seguir, é apresentada a organização das instituições públicas do país, através da atuação do Sistema Nacional de Arquivos (SINAR), as quais devem seguir as normativas instituídas pelo Conselho Nacional de Arquivos (CONARQ), órgão central do SINAR e pelo Arquivo Nacional, órgão central do Sistema de Gestão de Documentos de Arquivo (SIGA), da Administração Pública Federal, pois é desses órgãos que emanam as regulamentações e recomendações que regem as atividades de gestão de documentos da Administração Pública.

Na sequência, é apresentada a plataforma ICA-AtoM e sua utilidade nas atividades arquivísticas de difusão e descrição, bem como para proporcionar o acesso ao patrimônio documental de instituições públicas.

No último capítulo são realizadas considerações acerca da sua utilização na divulgação dos documentos arquivísticos custodiados por instituições

\footnotetext{
1 Blog do Grupo de Pesquisa Gestão Eletrônica de Documentos Arquivísticos - Ged/A. http://documentosarquivisticosdigitais.blogspot.com.br/.
} 
públicas, a qual serve à descrição do patrimônio documental, bem como à difusão, como forma de possibilitar o acesso dos documentos públicos à sociedade, como determina a Lei de Acesso à Informação.

\section{O SISTEMA NACIONAL DE ARQUIVOS (SINAR)}

A lei $n^{\circ}$ 8.159, de 8 de janeiro de 1991 - Lei de Arquivos, estabelece, em seu artigo primeiro que "é dever do Poder Público a gestão documental e a proteção especial a documentos de arquivo, como instrumentos de apoio à administração, à cultura, ao desenvolvimento científico e como elementos de prova e informação". (BRASIL, 1991).

Por esta lei,

[...] foram criados o Sistema Nacional de Arquivos (SINAR) e o Conselho Nacional de Arquivos (CONARQ), órgão central do Sistema, que tem por finalidade definir a política nacional de arquivos públicos e privados, conforme os decretos $n^{\circ} 1.173$, de 29 de junho de 1994, e 1.461, de 25 de abril de 1995". (BRASIL, 2001, p. 6).

Esses decretos foram revogados pelo Decreto $n^{\circ} 4.073$, de 3 de janeiro de 2002 (BRASIL, 2002), que no capítulo II regulamentou as competências, a organização e o funcionamento do Sistema Nacional de Arquivos. Nessa legislação é explicitado que o SINAR tem por finalidade implementar a política nacional de arquivos públicos e privados, visando à gestão, à preservação e o acesso aos documentos de arquivo.

O documento Subsídios para inserção do segmento dos arquivos no Programa Sociedade da Informação no Brasil (2001, p. 6) informa que,

[...] integram o SINAR todos os arquivos públicos do país, isto é, os arquivos dos poderes Executivo, Legislativo e Judiciário, em nível federal, estadual e municipal, bem como os de pessoas físicas e jurídicas de direito privado que a ele se filiem mediante convênio.

Strohschoen $(2008$, p. 8$)$, ao tratar sobre o funcionamento do Sistema Nacional de Arquivos afirma que: 
Para melhor funcionamento e maior agilidade na operacionalização do Sistema Nacional de Arquivos (SINAR), foi prevista a criação de Câmaras Técnicas e Câmaras Setoriais e Comissões Especiais, com a incumbência de elaborar estudos e normas necessárias à implementação da política nacional de arquivos públicos e privados e ao funcionamento do SINAR.

Nesse sentido, como aponta a página web do CONARQ (CONSELHO NACIONAL DE ARQUIVOS, 2016) na internet, foram constituídas Câmaras Técnicas para subsidiar as atividades de capacitação de recursos humanos, avaliação de documentos, classificação de documentos, documentos audiovisuais, iconográficos e sonoros, documentos eletrônicos, normalização da descrição arquivística, paleografia e diplomática e preservação de documentos.

Ao se referir sobre o Sistema Nacional de Arquivos, Silva (1999) informa que a consolidação desse Sistema supera a visão setorizada sobre os acervos arquivísticos, transformando cada instituição de guarda em co-responsável pela garantia do acesso a parcelas do patrimônio documental brasileiro e a sua preservação. De acordo com o autor, com a instituição do SINAR, os arquivos devem prever a preservação do documento enquanto fonte de informação que precisa ser disponibilizada, estando a questão da guarda vinculada diretamente às condições de tratamento técnico do acervo, pois documento recolhido, guardado e não organizado significa inexistência de informação.

Portanto, as instituições públicas, além de recolher, tratar e organizar os documentos arquivísticos, devem prever alternativas de disponibilizá-los à sociedade, e uma dessas possibilidades se dá através da utilização de uma plataforma que automatize a descrição, a difusão e o acesso, como o ICA-AtoM - (International Council Archives - Access to Memory), software livre desenvolvido a pedido do Conselho Internacional de Arquivos, o qual é apresentado a seguir.

\section{A PLATAFORMA DE DESCRIÇÃO, DIFUSÃO E ACESSO ICA-ATOM}

A tecnologia da informação vem ocasionando transformações em diversos segmentos da sociedade. $\mathrm{Na}$ área arquivística sua presença é 
marcante, tanto que ultimamente tem aumentado o quantitativo de instituições que fazem uso de sistemas informatizados, repositórios e plataformas que automatizam atividades como descrição, difusão, e que inclusive proporcionam o acesso ao patrimônio documental arquivístico.

Ao tratar sobre os softwares que instrumentalizam atividades arquivísticas, Flores e Hedlund (2014, p. 3) explicam que estes providenciam:

[...] um espaço confiável de guarda dos documentos digitais e uma nova forma de dar acesso ao patrimônio documental, suprindo algumas das principais necessidades dos atuais usuários de arquivo, principalmente pela existência de funcionalidades que facilitam e incrementam a pesquisa, aumentando o índice de recuperação da informação, bem como pela possibilidade de oferecer ao usuário um representante digital confiável e de alta qualidade visual. (FLORES; HEDLUND, 2014, p. 3).

Flores e Hedlund (2014) afirmam que as instituições arquivísticas têm utilizado a tecnologia da informação no auxílio das atividades arquivísticas, como por exemplo, na publicação dos produtos das descrições arquivísticas e os representantes digitais dos documentos na internet. Essa prática providencia o acesso fácil e rápido à documentação, além de evitar o manuseio excessivo do suporte analógico.

Nesse sentido, como indica Santos (2012, p. 111) "novos softwares surgem como ferramentas para colaborar na gestão, preservação e acesso às informações". Ao retratar o software livre, a pesquisadora explica que este "converte-se numa ferramenta promissora na área arquivística, ao tratar de metadados para o tratamento de conjuntos documentais arquivísticos". (SANTOS, 2012, p. 44).

Dessa forma, destaca-se a utilização de plataformas informatizadas para a difusão, descrição e acesso aos documentos de arquivo, tal como o ICAAtoM.

Ao explicar a origem do ICA-AtoM, Pavezi (2013) cita que esse projeto, acrônimo para Access to Memory, resultou de um esforço colaborativo entre o International Council of Archives - ICA e alguns parceiros e patrocinadores, como a UNESCO, a Escola de Arquivos de Amsterdam, o Banco Mundial, a 
Direção dos Arquivos de França, o Projeto Alouette Canadá e o Centro de Documentação dos Emirados Árabes Unidos.

Conrado (2014) complementa a explicação da pesquisadora, ao mencionar que o Conselho Internacional de Arquivos, junto com o arquivista canadense Peter Van Garderen, desenvolveu o software - ICA-AtoM acrônimo de Internacional Council of Archives - Access to Memory, buscando a automação e o consequente intercâmbio de informações entre instituições.

De acordo com Rodrigues (2014, p. 37) "o software resultante deste projeto teve sua primeira versão lançada em 2006, chamado de ICA-AtoM v.0.1. Por se tratar de um software livre, contempla liberdades para execução, adaptação, pesquisa, aperfeiçoamento e redistribuição de cópias". A pesquisadora ainda complementa afirmando que desde o lançamento da versão 1.0 beta do software, em 2008, diversas versões foram lançadas ao longo dos últimos anos, passando pela 1.1, 1.2, 1.3 até a 1.4, lançada em 2013. Desde então, quando passou a denominar-se apenas AtoM, até 2015 foram lançadas as versões 2.0, 2.1 e 2.2, sendo que atualmente, a versão mais recente da ferramenta, lançada em fevereiro de 2016, é a 2.2.1.

Hedlund e Flores (2014, p. 30) explicam que na versão 2.0, "versão estável do ICA-AtoM, além de o software não ser mais vinculado ao ICA, foram acrescentadas novas funcionalidades e corrigidas algumas dificuldades de funcionamento das versões anteriores".

Segundo Conrado (2014, p. 36):

[...] dentre as melhorias do AtoM quando comparado à última versão, destaca-se a funcionalidade de repositório digital aliando a descrição arquivística ao seu representante digital ou ao documento digital, condensando, assim, descrição e documento em único software.

Na opinião de Hedlund e Flores (2014, p. 30), o visual da nova versão "ficou mais moderno, as buscas tornaram-se mais rápidas e dinâmicas devido ao Elasticsearch (um servidor de buscas distribuído), possuindo mais opções para refinar a recuperação da informação pelo usuário".

Ao apresentar a visão geral da plataforma, Pavezi (2013) explica que o ICA-AtoM compreende: 
1. Páginas HTML servidas para um navegador de internet a partir de um servidor de internet. O servidor web Apache foi usado para o desenvolvimento, mas o ICA-AtoM também é compatível com o IIS, 2. Toda a interação do usuário com o sistema (criar, visualizar, pesquisar, atualizar e excluir) é realizada no navegador de internet do usuário, 3. O ICA-AtoM foi desenvolvido com ferramentas de código aberto (Apache, MySQL, PHP, Symfony) em vez de softwares comerciais com direito de propriedade, 4. O ICA-AtoM foi desenvolvido em torno das normas de descrição do International Council on Archives (ICA), bem como para ser suficientemente flexível para a adaptação de outras normas de descrição, 5 . Todas as interfaces de usuários, elementos e conteúdo da base de dados podem ser traduzidos para diferentes idiomas, 6. O ICAAtoM pode ser usado por uma única Instituição, para a sua própria descrição, ou pode ser definido como um multiarquivos ou multirrepositório, aceitando descrições de qualquer número de instituições arquivísticas.

De acordo com Hedlund e Flores (2014, p. 31) "o ICA-AtoM utiliza procedimentos simples das tecnologias para internet oferecidas atualmente. Desse modo, a partir de seu navegador de internet padrão e acesso à internet, é possível utilizar todos os recursos disponíveis no software". O ICA-AtoM "destaca-se por ser um software aplicativo, de código aberto e projetado para funcionar em ambiente web, além de ser uma ferramenta multilíngue podendo ser utilizado por uma única instituição ou ser um ambiente multiarquivos". (RODRIGUES, 2014, p. 78).

Destinado à descrição arquivística, segundo Conrado (2014) o ICA-AtoM é um software de formato aberto, desenvolvido de acordo com a ISAD (G), ISAAR (CPF) e ISDIAH do Conselho Internacional de Arquivos, possuindo distribuição gratuita através do endereço eletrônico <https://www.icaatom.org/>. Atualmente, a versão estável da plataforma é disponibilizada para download no endereço <https://www.accesstomemory.org/pt-br/>.

Seu objetivo, de acordo com Pavezi (2013) é dotar a comunidade arquivística internacional de um software de formato aberto que permita descrever os arquivos em conformidade com as normas do ICA (ISAD, ISAAR, ISIAH, ISAF), possibilitando a disponibilização online do acervo das instituições arquivísticas. 
Na opinião de Flores e Hedlund (2014, p. 24) a plataforma ICA-AtoM "é disponibilizada gratuitamente para que as instituições tenham uma alternativa rápida e simples para dar acesso à sua documentação aos usuários". Os pesquisadores ainda explicam que:

O ICA-AtoM possui uma gama de recursos técnicos que flexibilizam e facilitam a atividade de descrição arquivística, auxilia na preservação dos documentos originais e na difusão de informações sobre o acervo, ao providenciar o acesso à documentação por meio de representantes digitais, permitindo assim um alcance global através de sua interface multilíngue na internet. (HEDLUND; FLORES, 2014, p. 24).

Por outro lado, Rodrigues (2014, p. 38) entende que seu principal objetivo "é oferecer à comunidade arquivística internacional um software livre que permita às instituições a disponibilização web das informações de seus fundos documentais, propiciando o acesso ao patrimônio arquivístico documental".

Doutra parte, Conrado (2014) chama atenção para o fato da plataforma ICA-AtoM ser compatível com outros softwares, como repositórios digitais, podendo ser utilizado por qualquer instituição para a descrição e difusão do patrimônio documental arquivístico. Como mencionado por Hedlund (2014) que indica que é possível integrar o ICA-AtoM com o software Archivematica, o qual é um "repositório digital que foi construído com o objetivo de armazenar a documentação em formato digital, seguindo os padrões exigidos em relação à preservação desta, visando torná-la acessível a longo prazo". (HEDLUND, 2014, p. 60). No entanto, Flores e Hedlund (2014) acreditam que:

[...] a falta de conhecimento sobre essas duas ferramentas arquivísticas e o receio de trabalhar com a tecnologia da informação - seja talvez pela iminente ideia de altos custos financeiros ou por se tratar de algo em constante transformação o que exige atualizações periódicas - fazem com que muitas instituições arquivísticas não utilizem ou deixem em segundo plano a utilização de ferramentas arquivísticas como essas. (FLORES; HEDLUND, 2014, p. 1).

Porém, os pesquisadores alertam que "cabe atentar para o fato de que o uso de sistemas informatizados na preservação digital e na difusão do 
patrimônio documental é uma maneira eficiente de satisfazer as principais necessidades dos atuais usuários de arquivo". (FLORES; HEDLUND, 2014, p. 29). Por ser uma ferramenta que usa a web como plataforma, Conrado (2014) explica que o ICA-AtoM é uma opção bastante consistente quando se fala em difusão de arquivos, pois:

A difusão através das ferramentas que utilizam a web, tais como ICA-AtoM, sítios institucionais, redes sociais, entre outros, representam um custo baixo ou até mesmo, custo zero. Além disso, potencialmente, o número de usuários reais e usuários em potencial a serem atingidos é maior, uma vez que as barreiras geográficas são quebradas pela internet. Mesmo assim, são poucas as instituições que utilizam essas plataformas para alcançar seus usuários. (CONRADO, 2014, p. 96).

Entretanto, a pesquisadora compreende que "a ferramenta ICA-AtoM, além de se mostrar eficiente e de fácil utilização, traz diversas possibilidades e soluções a baixo custo para instituições arquivísticas". (CONRADO, 2014, p. 96).

Um dos pontos mais importantes da plataforma ICA-AtoM, de acordo com Hedlund e Flores (2014) é a conformidade com as normas de descrição arquivística recomendadas pelo ICA. Essas normas surgiram "por volta da década de 1980, pois com o avanço da informática dentro dos arquivos sentiuse a necessidade de normalização para a descrição arquivística. (FLORES; HEDLUND, 2014, p. 15). Conforme os pesquisadores, as normas de descrição arquivística contempladas atualmente por essa ferramenta são:

[...] a International Standard Archival Description (General) $\left(2^{\mathrm{a}}\right.$ edição, 1999) - ISAD (G), a International Standard Archival Authority Record for Corporate Bodies, Persons, and Families (2a edição, 2003) - ISAAR (CPF), a International Sustainable Development Foundation ( $1^{\mathrm{a}}$ edição, 2007) - ISDF e a International Standard for Describing Institutions with Archival Holdings (1ª edição, 2008) - ISDIAH. (HEDLUND; FLORES, 2014, p. 30).

Rodrigues (2014) explica que o ICA-AtoM ao ser desenvolvido a partir das normas internacionais de descrição arquivística, permite que as instituições 
arquivísticas criem seus instrumentos de pesquisa online, e por ser bastante flexível, adapta-se a outras normas mais específicas, como é o caso da Norma Brasileira de Descrição Arquivística - NOBRADE. Menção que também é realizada por Pavezi (2010) ao explicitar que a estrutura dos elementos descritivos da plataforma corresponde exatamente à norma internacional para descrição de arquivos ISAD (G) cuja estrutura está contemplada também pela NOBRADE. Ao constatar a compatibilidade do ICA-AtoM com a NOBRADE, Flores e Hedlund (2014, p. 28) indicam que "o arquivista brasileiro, ou qualquer outra pessoa que deseja promover o patrimônio documental sob sua custódia, tem em suas mãos uma ferramenta de trabalho gratuita e pautada pelas recomendações arquivísticas, sem a necessidade de desenvolver ou adquirir um software no mercado".

Além disso, como indicado por Hedlund (2014, p. 126), o ICA-AtoM é "um software livre que utiliza como dependências outros softwares livres, o que favorece a adoção pelas instituições por não ser dependente de empresas proprietárias, sendo uma alternativa para diminuir o aprisionamento tecnológico imposto pela indústria dominante". Ademais, "quando comparado com soluções comerciais, o ICA-AtoM permite explorar enormes potencialidades por uma fração de custo das soluções proprietárias, e pautado pelas normas de descrição arquivística". (HEDLUND, 2014, p. 126).

O pesquisador explica que "há muitas vantagens em utilizá-lo na descrição arquivística, pois há funcionalidades que enriquecem e facilitam a inserção e apresentação final da descrição arquivística para o usuário, além de contemplar as principais normas internacionais de descrição arquivística. (HEDLUND, 2014, p. 126). Nesse sentido, como ressalta Conrado (2014) as aplicações AtoM representam um grande salto evolutivo na elaboração, disponibilização e difusão dos instrumentos arquivísticos, uma vez que:

[...] as normas internacionais de descrição arquivística foram sistematizadas para aplicação em ambiente digital através do ICA-AtoM. Isso representa para a comunidade arquivística a possibilidade efetiva de adoção das normas internacionais e o efetivo intercâmbio de informações - premissa destas normas. (CONRADO, 2014, p. 36). 
Hedlund e Flores (2014) explicam que o software ICA-AtoM auxilia a atividade de descrição arquivística, possibilitando o acesso via internet à informação/documentação por ele gerenciada, contemplando ainda as características principais da descrição arquivística definidas pelo ICA: identificação, gerência, localização e explicação do documento, do contexto e do sistema de arquivo em que ele foi produzido.

Por ser totalmente baseada na web, "a ferramenta permite que as instituições disponibilizem as informações contidas em seus acervos em meio eletrônico, possibilitando desta forma o intercâmbio de informações entre instituições e o acesso de um grande número de usuários". (RODRIGUES, 2014, p. 79). Doutra parte, como indica Conrado (2014, p. 36) "para o cidadão, as aplicações AtoM denotam a garantia do direito constitucional de acessar informações, aproximando usuários de arquivos, quebrando, inclusive, barreiras geográficas". Além disso, a pesquisadora complementa que, por ser um software livre, o ICA-AtoM "atende as políticas de preservação dos documentos arquivísticos, uma vez que prima pelo acesso, pela liberdade, pela possibilidade de migração e conversão, corroborando, assim, para a preservação dos documentos arquivísticos digitais, inclusive". (CONRADO, 2014, p. 99).

Por outro lado, Flores e Hedlund (2014) afirmam que os instrumentos eletrônicos de pesquisa constituíram-se em poderosas ferramentas e sua aplicação vem crescendo rapidamente nas instituições arquivísticas brasileiras. Os pesquisadores acrescentam dizendo que "com a internet, as potencialidades dessas ferramentas aumentam, ganhando uma nova dimensão, podendo aproximar ainda mais o usuário ao arquivo e fazê-lo até participar diretamente do processo de criação e/ou revisão da descrição arquivística". (FLORES; HEDLUND, 2014, p. 28).

Além disso, "usuários podem por intermédio da internet, comunicar-se, dando sugestões de melhorias e aperfeiçoamentos para o software, podendo até os próprios usuários realizarem as modificações que necessitarem". (HEDLUND, 2014, p. 102). Nesse sentido, "o uso adequado do ICA-AtoM, se aplicado de acordo com critérios arquivísticos exigidos, pode facilitar atividades 
e trazer benefícios à instituição detentora do acervo". (HEDLUND; FLORES, 2014, p. 24).

Ao tratar sobre a utilização do ICA-AtoM, Conrado (2014) informa que nos últimos anos, diversas pesquisas baseadas em estudos de caso de instituições que adotaram o ICA-AtoM como solução de descrição arquivística e de difusão de acervos consolidaram o software entre a comunidade arquivística, tanto que atualmente o número de instituições que o utilizam vem crescendo, o que proporcionará num futuro próximo, um cenário jamais vislumbrado: a integração e o efetivo intercâmbio de informações a partir da automação das normas internacionais de descrição arquivística e de sua automação em rede proporcionada pelo ICA-AtoM.

Ademais, a Orientação Técnica n 3 , de novembro de 2015 da Câmara Técnica de Documentos Eletrônicos do Conselho Nacional de Arquivos (CTDE/CONARQ), lembra que a preservação dos documentos arquivísticos digitais, nas idades corrente, intermediária e permanente, deve estar associada a um repositório digital confiável, devendo os arquivos dispor de repositórios digitais confiáveis para a gestão, a preservação e o acesso de documentos digitais (CONSELHO NACIONAL DE ARQUIVOS, 2015).

Para que a gestão, a preservação e acesso aos documentos digitais sejam garantidos, deve ser mantida a cadeia de custódia ininterrupta, que de acordo com Flores (2016) é a

[...] linha contínua de custodiadores de documentos arquivísticos (desde o seu produtor até o seu legítimo sucessor) pela qual se assegura que esses documentos são os mesmos desde o início, não sofreram nenhum processo de alteração e, portanto, são autênticos.

Portanto, a plataforma de acesso e difusão ICA-AtoM quando interconexa a um RDC-Arq, como o Archivematica, por exemplo, garantirá a manutenção da cadeia de custódia digital, através da disponibilização online da documentação após a gestão em um SIGAD, e a preservação em um repositório arquivístico digital dos documentos permanentes, bem como os correntes e intermediários de longas temporalidades, provendo assim, 
autenticidade e acesso a longo prazo aos documentos arquivísticos digitais (Figura 1).

Figura 1 - Cadeia de custódia dos documentos digitais

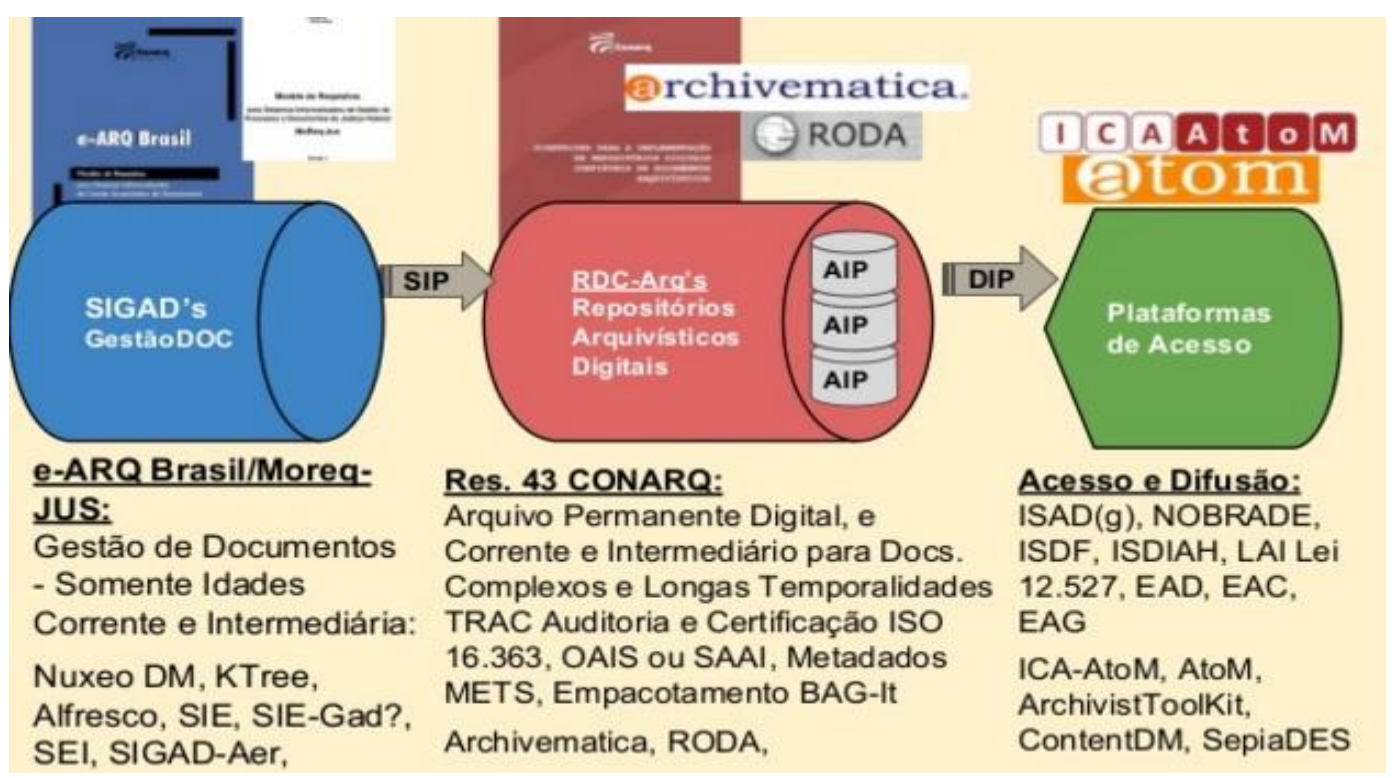

Fonte: Flores (2016).

Dessa forma, estará garantida a integridade, a autenticidade, a confidencialidade, a disponibilidade e a preservação dos documentos produzidos e acumulados no âmbito público, ou seja, ao ser interligado ao Repositório Arquivístico Digital Archivematica, o ICA-AtoM proporcionará uma forma de ter um ambiente autêntico para o armazenamento seguro e como fonte de prova dos documentos digitais.

\section{CONSIDERAÇÕES FINAIS}

O Decreto $n^{0} 7.724$, de 16 de maio de 2012, que regulamentou a LAl, determinou que é dever dos órgãos públicos promover, independentemente de requerimento, a disponibilização de informações de interesse geral ou coletivo por eles produzidas ou custodiadas (BRASIL, 2012). Ou seja, documentos correntes, onde constam informações referentes à administração do patrimônio público e utilização de recursos públicos como licitações (realizadas e em andamento), editais (anexos e resultados), além de contratos firmados, notas 
de empenho emitidas, entre outros, devem ser colocados à disposição da sociedade para conhecimento. Nesse sentido, o ICA-AtoM é uma solução eficaz para tornar públicas essas informações, principalmente as decorrentes da tramitação de processos de compra e licitação em andamento, como forma de as instituições públicas promoverem a transparência ativa, conforme preceitua a legislação. Essa perspectiva corrobora com o pensamento de Conrado (2014, p. 36) quando afirma que "para o cidadão, as aplicações AtoM denotam a garantia do direito constitucional de acessar informações, aproximando usuários de arquivos, quebrando, inclusive, barreiras geográficas".

O ICA-AtoM, inicialmente pensado para automatizar a atividade de descrição arquivística, vem evoluindo como solução de acesso aos documentos de arquivo, tanto que o ATOM já pode ser considerado uma plataforma de acesso e difusão das informações custodiadas pelas instituições públicas, servindo como meio de possibilitar o acesso dos documentos públicos à sociedade, como determina a Lei de Acesso à Informação. Tanto que Flores e Hedlund (2014) afirmam que a plataforma é disponibilizada para que as instituições tenham uma alternativa rápida e simples para dar acesso à sua documentação. Ideia que também é compartilhada por Rodrigues (2014) quando indica que seu principal objetivo é permitir que as instituições disponibilizem as informações de seus fundos documentais, propiciando o acesso ao patrimônio documental arquivístico.

Essa plataforma, desenvolvida em conformidade com normas de descrição e metadados de padrões internacionais permite a descrição arquivística em níveis hierárquicos (fundos, séries, dossiês/processos, itens documentais). Entretanto, a plataforma em si não operacionaliza a gestão de documentos (papel de um SIGAD), não garante a autenticidade, e tampouco a preservação de longo prazo (papel de um RDC-Arq).

No entanto, os órgãos e entidades integrantes do Sistema Nacional de Arquivos (SINAR), como determinado pela Resolução $n^{\circ} 20$ do CONARQ, de 16 de julho de 2004 (CONSELHO NACIONAL DE ARQUIVOS, 2004), devem identificar entre os documentos digitais, aqueles considerados arquivísticos 
para que sejam contemplados no Programa de Gestão Arquivística de Documentos (PGAD), sendo que esse programa deve prever a implantação de um Sistema Informatizado de Gestão Arquivística de Documentos (SIGAD), desenvolvido de acordo com os requisitos do Modelo de Requisitos para Sistemas Informatizados de Gestão Arquivística de Documentos (e-ARQ Brasil), o qual fará a gestão dos documentos arquivísticos em fase corrente e intermediária até a destinação para um Repositório Arquivístico Digital Confiável (RDC-Arq), para arquivamento e manutenção daqueles considerados permanentes e dos intermediários com longas temporalidades, conforme recomendações das Resoluções n 39/CONARQ/2014 e n 43/CONARQ/2015 (CONSELHO NACIONAL DE ARQUIVOS, 2015).

O Decreto $n^{\circ}$ 8.539, de 8 de outubro de 2015 da Casa Civil da Presidência da República, que dispõe sobre o uso do meio eletrônico para a realização do processo administrativo no âmbito dos órgãos e entidades da administração pública federal, também prevê que documentos digitais e processos administrativos eletrônicos já encerrados e que estejam aguardando o cumprimento dos prazos de guarda e destinação final, poderão ser transferidos para uma área de armazenamento específica, sob controle do órgão que os produziu, a fim de serem preservados, seguros e acessíveis pelo tempo necessário (BRASIL, 2015). Nesse sentido, entende-se que essas instituições devem observar as Resoluções $n^{\circ}$ 39/CONARQ/2014 e $n^{\circ}$ 43/CONARQ/2015, que estabelecem diretrizes para a implementação de repositórios arquivísticos digitais confiáveis para o arquivamento e manutenção dos documentos arquivísticos digitais.

Hedlund (2014, p. 60) já havia indicado que é possível integrar o ICAAtoM com o software Archivematica, que é um "repositório digital que foi construído com o objetivo de armazenar a documentação em formato digital, seguindo os padrões exigidos em relação à preservação desta, visando tornála acessível a longo prazo".

Portanto, se a plataforma ICA-AtoM for interconexa a um RDC-Arq, como o Archivematica, por exemplo, garantirá a autenticidade, a manutenção da cadeia de custódia e o acesso a longo prazo dos documentos arquivísticos 
digitais permanentes, pois o Archivematica é um sistema de preservação digital que pode ser utilizado inclusive, para o arquivamento e a manutenção de documentos arquivísticos digitais em fases corrente e intermediária, conforme recomenda a Resolução $n^{\circ} 43 / C O N A R Q / 2015$. Pois, esta normativa indica que assim estará garantida a integridade, a autenticidade, a confidencialidade, a disponibilidade e a preservação dos documentos produzidos e acumulados no âmbito público, ou seja, ao ser interligado ao Repositório Arquivístico Digital Archivematica, o ICA-AtoM proporcionará uma forma de ter um ambiente autêntico para $o$ armazenamento seguro e como fonte de prova das mensagens de correio eletrônico institucionais, documentos digitais e digitalizados, bem como para prover preservação e acesso a longo prazo, pois - ICA-AtoM "atende as políticas de preservação dos documentos arquivísticos, uma vez que prima pelo acesso, pela liberdade, pela possibilidade de migração e conversão, corroborando, assim, para a preservação dos documentos arquivísticos digitais, inclusive". (CONRADO, 2014, p. 99).

Dessa forma, ao ser contemplado no Programa de Gestão Arquivística de Documentos (PGAD) da instituição, o ICA-AtoM garantirá a manutenção da cadeia de custódia digital, através da disponibilização online da documentação após a gestão em um SIGAD, e a preservação em um repositório dos documentos permanentes, bem como os correntes e intermediários de longas temporalidades. Pois, como indicado por Hedlund e Flores (2014) o uso adequado do ICA-AtoM, se aplicado de acordo com critérios arquivísticos exigidos, pode facilitar as atividades e trazer benefícios à instituição detentora do acervo.

Nesse sentido, as instituições públicas através da adoção dessa plataforma cumprirão preceitos arquivísticos de preservação, difusão e acesso aos documentos institucionais, contribuindo para a promoção da transparência das informações por elas produzidas e custodiadas, pois essa solução é compreendida como uma plataforma de acesso à informação, que possibilita a transparência ativa ou passiva das informações, a difusão e a descrição de documentos de arquivo, além de contemplar a Lei de Acesso à Informação. 


\section{REFERÊNCIAS}

BRASIL. Conselho Nacional de Arquivos. Subsídios para inserção do segmento dos arquivos no Programa Sociedade da Informação no Brasil. Rio de Janeiro, 2001. Disponível em:

<http://www. arquivonacional.gov.br/Media/livroverdeconarq.pdf>. Acesso em: 21 mar. 2016.

BRASIL. Decreto $n^{\circ} 4.073$, de 3 de janeiro de 2002. Regulamenta a Lei $n^{\circ}$ 8.159, de 8 de janeiro de 1991, que dispõe sobre a política nacional de arquivos públicos e privados. Disponível em:

$<$ http://www.planalto.gov.br/ccivil_03/decreto/2002/d4073.htm>. Acesso em: 21 mar. 2016.

BRASIL. Decreto $n^{\circ} 7.724$, de 16 de maio de 2012. Regulamenta a Lei $n^{\circ}$ 12.527, de 18 de novembro de 2011, que dispõe sobre o acesso a informações. Disponível em: <http://www.planalto.gov.br/ccivil_03/_ato20112014/2012/Decreto/D7724.htm>. Acesso em: 29 out. 2015.

BRASIL. Decreto $n^{\circ} \mathbf{8 . 5 3 9}$, de 8 de outubro de 2015. Dispõe sobre o uso do meio eletrônico para a realização do processo administrativo no âmbito dos órgãos e entidades da administração pública federal direta, autárquica e fundacional. Disponível em: <http://www.planalto.gov.br/ccivil_03/_Ato20152018/2015/Decreto/D8539.htm>. Acesso em: 21 mar. 2016.

BRASIL. Lei $n^{\circ} 8.159$, de 8 de janeiro de 1991. Dispõe sobre a política nacional de arquivos públicos e privados e dá outras providências. Disponível em: <http://www.planalto.gov.br/ccivil_03/LEIS/L8159.htm >. Acesso em: 1 nov. 2015 .

CONRADO, Flávia Helena. Arranjo, descrição e difusão do patrimônio documental arquivístico da Universidade Federal do Rio Grande do Sul. 2014. Dissertação (Mestrado em Patrimônio Cultural) - Universidade Federal de Santa Maria, Santa Maria, 2014.

CONSELHO NACIONAL DE ARQUIVOS (Brasil). Disponível em: <http://conarq.gov.br/>. Acesso em: 11 abr. 2016.

CONSELHO NACIONAL DE ARQUIVOS (Brasil). Orientação técnica $\mathbf{n}^{\circ} \mathbf{3}$, novembro de 2015. Cenários de uso de RDC-Arq em conjunto com o SIGAD. Disponível em: <http://www.conarq.arquivonacional.gov.br/orientacoestecnicas/456-cenarios-de-uso-de-rdc-arq-em-conjunto-com-o-sigad.html>. Acesso em: 11 abr. 2016. 
CONSELHO NACIONAL DE ARQUIVOS (Brasil). Resolução $n^{\circ}$ 20, de 16 de julho de 2004. Dispõe sobre a inserção dos documentos digitais em programas de gestão arquivística de documentos dos órgãos e entidades integrantes do Sistema Nacional de Arquivos. Disponível em: $<$ http://www.conarq.gov.br/legislacao/resolucoes-do-conarq/262-resolucao-n20,-de-16-de-julho-de-2004.html>. Acesso em: 21 mar. 2016.

CONSELHO NACIONAL DE ARQUIVOS (Brasil). Resolução $n^{\circ}$ 43, de 04 de setembro de 2015. Altera a redação da Resolução do CONARQ no 39, de 29 de abril de 2014, que estabelece diretrizes para a implementação de repositórios digitais confiáveis para a transferência e recolhimento de documentos arquivísticos digitais para instituições arquivísticas dos órgãos e entidades integrantes do Sistema Nacional de Arquivos - SINAR. Disponível em: <http://www.conarq.arquivonacional.gov.br/cgi/cgilua.exe/sys/start.htm> Acesso em: 10 dez. 2015.

FLORES, Daniel. A difícil tarefa de manter a cadeia de custódia digital dos documentos arquivísticos: autênticos ou autenticados. Rio de janeiro, 2016. Disponível em: <http://pt.slideshare.net/dfloresbr/a-difcil-tarefa-de-manter-acadeia-de-custdia-digital-dos-documentos-arquivsticos-autnticos-ouautenticados>. Acesso em: 11 abr. 2016.

FLORES, Daniel; HEDLUND, Dhion Carlos. A preservação do patrimônio documental através da produção de instrumentos de pesquisa arquivísticos e da implementação de repositórios arquivísticos digitais. Série Patrimônio Cultural e Extensão Universitária, Brasília, n. 3, fev. 2014. Disponível em: <http://portal.iphan.gov.br/uploads/publicacao/SerPatExt_n3_m.pdf>. Acesso em: 25 set. 2015.

HEDLUND, Dhion Carlos. O patrimônio fotográfico de Santa Maria em ambiente digital. 2014. Dissertação (Mestrado em Patrimônio Cultural) Universidade Federal de Santa Maria, Santa Maria, 2014.

HEDLUND, Dhion Carlos; FLORES, Daniel. Análise e aplicação do Software Livre ICA-AtoM como ferramenta para descrição e acesso às informações do patrimônio documental e histórico do município de Santa Maria - RS.

Informação Arquivística, Rio de Janeiro, v. 3, n. 1, p. 24-41, jan./jun. 2014. Disponível em:

$<$ http://www.aaerj.org.br/ojs/index.php/informacaoarquivistica/article/view/63/30 >. Acesso em: 25 out. 2015.

PAVEZI, Neiva. Arquivo fotográfico: uma faceta do patrimônio cultural da UFSM. 2010. Dissertação (Mestrado Profissional em Patrimônio Cultural) Universidade Federal de Santa Maria, Santa Maria, 2010. 
PAVEZI, Neiva. ICA-AtoM: manual do usuário em língua portuguesa-BR. Santa Maria: UFSM, 2013. Disponível em: <http://w3.ufsm.br/dag/images/ICAAtoM\%20manual\%20do\%20usuario\%20-\%20PT\%20BR.pdf>. Acesso em: 25 out. 2015.

RODRIGUES, Camila Poerschke. A UFSM no Projeto Rondon: acesso web ao patrimônio documental arquivístico. 2014. Dissertação (Mestrado Profissional em Patrimônio Cultural) - Universidade Federal de Santa Maria, Santa Maria, 2014.

SANTOS, Andrea Gonçalves dos. Descrevendo o patrimônio documental da FURG: Faculdade de Direito Clovis Bevilaqua (1959 - 1972). 2012. Dissertação (Mestrado em Patrimônio Cultural) - Universidade Federal de Santa Maria, Santa Maria, 2012.

SILVA, Jaime Antunes. Por uma política nacional de arquivos. 1999. Disponível em: <http://www.conarq.arquivonacional.gov.br/Media/publicacoes/mesa/por_uma_ poltica_nacional_de_arquivos.pdf>. Acesso em: 27 set. 2015.

STROHSCHOEN, Cristina. Gestão arquivística em universidades comunitárias. In: COLÓQUIO INTERNACIONAL SOBRE GESTÃO UNIVERSITÁRIA NA AMÉRICA DO SUL, 8., 2008, Florianópolis. Anais... Florianópolis: UFSC, 2008. Disponível em: <https://repositorio.ufsc.br/handle/123456789/64284>. Acesso em: 21 ago. 2013.

Title

The Ica-Atom using as access platform, dissemination and description of archival documents public institutions

\begin{abstract}
Introduction: Information technology has caused changes in various segments of society. In archival area its presence is remarkable, so much that lately has increased the quantity of institutions that make use of computerized systems, repositories and platforms that automate activities such as description, diffusion, and even provide access to archival documentary heritage.

Objective: To discuss the functionality and usefulness of the platform International Archives Council - Access to Memory (ICA-AtoM) in archival description of activities, dissemination and access to archival documentary heritage.

Methodology: bibliographical research, drawn from the archival legislation, especially through research resulting from Master's dissertations, articles published in journals of the Science field of Information and manuals produced by members of the Group of CNPq-UFSM Research: Electronic Management of archival documents - Ged / A.

Results: It was observed that the platform is used to describe both the permanent documents, and to provide access to information recorded in current and intermediate documents, in order to streamline access to documentary resources of public institutions.
\end{abstract}


Conclusions: It is considered that the ICA-Atom besides serving the description, can provide an authentic environment for the secure storage and as a source of evidence of digital and digitized institutional documents, as well as to provide for preservation and long term access if It is connected to a RDC-Arq, like Archivematica, for example.

Keywords: ICA-AtoM. Access. Diffusion. Documentary heritage. Public institutions.

\section{Titulo}

La utilización de Ica-Atom como plataforma de acceso, difusión y descripción de documentos de archivo de instituciones públicas

\section{Resumen}

Introducción: La tecnología de la información ha provocado cambios en diversos segmentos de la sociedad. En el área de archivos su presencia es notable, tanto que últimamente ha aumentado la cantidad de instituciones que hacen uso de sistemas computarizados, repositorios y plataformas que automatizan actividades como la descripción, difusión, e incluso dan acceso al patrimonio documental de archivo.

Objetivo: Discutir la funcionalidad y utilidad de la plataforma del Consejo Internacional de Archivos - El acceso a la memoria (ICA-AtoM) en la descripción archivística de las actividades, la difusión y el acceso al patrimonio documental de archivo.

Metodología: investigación bibliográfica, extraído de la legislación sobre archivos, especialmente a través de la investigación resultante de la tesis de maestría, artículos publicados en revistas del campo de las Ciencias de la Información y manuales producidos por los miembros del Grupo de Investigación del CNPq-UFSM: gestión electrónica de documentos de archivo - Ged / A.

Resultados: Se observó que la plataforma se utiliza para describir tanto los documentos permanentes, y para facilitar el acceso a la información registrada en los documentos actuales e intermedios, con el fin de agilizar el acceso a los recursos documentales de las instituciones públicas.

Conclusiones: Se considera que el ICA-Atom además de servir la descripción, puede proporcionar un ambiente auténtico para el almacenamiento seguro y como fuente de evidencia de los documentos institucionales digitales y digitalizados, así como para proporcionar la preservación y largo plazo el acceso si está conectado a un RDC-Arq, como Archivematica, por ejemplo.

Palabras clave: ICA-AtoM. Acceso. Difusión. Patrimonio documental. Instituciones públicas.

Recebido em: 10.04 .2016

Aceito em: 18.11.2016 